\title{
Process Evaluation Study of Multiple-Systems Collaborative Child Welfare Approach: A Perspective on Foster Care Service Delivery \\ Kui Hee Song, Ph.D
}

Professor, School of Social Work, California State University, Chico, 400 W. First Street, Chico, California, United States.

\author{
Article Details \\ Article Type: Research Article \\ Received date: $13^{\text {th }}$ November, 2019 \\ Accepted date: $12^{\text {th }}$ December, 2019 \\ Published date: $14^{\text {th }}$ December, 2019
}

"Corresponding Author: Kui Hee Song, Professor, School of Social Work, California State University, Chico, 400 W. First Street, Chico, California 95929, United States. E-mail: ksong@,csuchico.edu

Citation: Song KH (2019) Process Evaluation Study of Multiple-Systems Collaborative Child Welfare Approach: A Perspective on Foster Care Service Delivery. J Ment Health Soc Behav 1: 107. https://doi.org/10.33790/jmhsb1100107

Copyright: (C2019, This is an open-access article distributed under the terms of the Creative Commons Attribution License 4.0, which permits unrestricted use, distribution, and reproduction in any medium, provided the original author and source are credited.

\begin{abstract}
s
It has become essential for those in child welfare policy development to understand models of collaboration processes in foster care programs, if they are to help programs succeed and improve outcomes for children and families in foster care. This paper presents a qualitative evaluation model used by the Local Interagency Network for Children's Services (LINCS), in Shasta County, California, as an example of evaluation of multisystems collaboration in child welfare services. This evaluation of a multisystems service delivery process includes key findings regarding day-to-day operations, financial relationships, and working relationships, as well as a comparison of the prior foster care services delivery system and the LINCS program. Lessons learned, recommendations, and implications for knowledge of the foster care service delivery process and evaluation research of foster care programs are included.
\end{abstract}

\section{Introduction}

According to Child Welfare Information Gateway [1], there were an estimated 427,910 children in foster care system in the United States on September 30, 2015. Of these, $42 \%$ were White, $24 \%$ were Black, 21\% were Hispanic (of any race), and $10 \%$ were other races or multiracial (Alaska Native/American Indian, Asian, Hawaiian/Other Pacific Islander, two or more races). $30 \%$ were in relatives' foster family homes, and $45 \%$ were in nonrelative foster family homes. $55 \%$ had a case plan goal of reunification with parent(s) or principal caretaker(s), and of the estimated 243,060 children who exited foster care system $51 \%$ were reunited with their parent(s) or primary caretaker(s). Close to half of the children (46\%) who left foster care in fiscal year (FY) 2015 were in care for less than 1 year. Of all the children in care, $22 \%$ were adopted, $9 \%$ were emancipated, $6 \%$ went to live with another relative, $9 \%$ went to live with a guardian, and $2 \%$ had other outcomes (being transferred to another agency, running away, death).

In California in 2015, 379,806 total referrals for child abuse and neglect. Of those, 235,297 reports were referred for investigation. 55,983 children lived apart from their families were in out-ofhome care in 2015. Of children in out-of-home care in California, $21 \%$ were white, $19 \%$ were black, $53 \%$ were Hispanic, $1 \%$ were American Indian/Alaskan Native, $2 \%$ were Asian or Pacific Islander and $5-6 \%$ were of more than one race or ethnicity/undetermined race or ethnicity. Of the 30,317 children exiting out-of-home care in 2014 in California, 56\% were reunited with their parents or primary caretakers. 6,079 children were legally adopted through a public child welfare agency in California in 2015. Of the 55,983 children in out-of-home care in 2015 , there were 14,180 or $25.3 \%$ waiting to be adopted. In 2015, approximately 272,320 grandparents in California had the primary responsibility of caring for their grandchildren.18, 532 of the children in out-of-home care in 2014 were living with relatives while in care [2].

This broke down as 27,566 Hispanic children (48.7 \%), 12,307 White (21.7\%), 11,850 Black (20.9\%), 134 Asian (2.0\%), 516 Native American (1.3\%), 2,801 Not Hispanic: Mixed (4.9\%), and 321 missing $(0.5 \%)$. Ninety percent of these children were served in the following various placement types: 20,635 (36.6\%) in kinship care; $14,663(26 \%)$ in foster family agency/foster family certified home care; 5,244 (9.7\%) in foster homes; 4,801 (8.6\%) in guardian-other care; $3,748(6.6 \%)$ in group homes; and 1,902 (3.4\%) in guardiandependent care. In addition, $10 \%$ of children served were in the following placements: $1,300(2.3 \%)$ in pre-adoption; $811(1.4 \%)$ in runaway; $884(1.6 \%)$ in supervised independent living placement; $820(1.5 \%)$ in "other"; $598(1.1 \%)$ in court-specified home; 515 $(0.9 \%)$ in trial home visit; $260(0.5 \%)$ in nonfoster care; $178(0.3 \%)$ in transitional housing; and $136(0.2 \%)$ in shelter [3].

Children who enter the foster care system are among America's most vulnerable and disadvantaged. These children experience prolonged, multiple, and complex issues with mental health and behavioral problems, educational achievement, housing, and employment, as well as criminal justice involvement and public assistance dependency [4-6]. However, most foster care services and programs take a basic, segregated, short-term, crisis-oriented approach. Numerous impact studies of the foster care system reveal discouraging results. Generally, children and youth in foster care are more likely to experience homelessness, poverty, compromised health, unemployment, and incarceration after they leave the foster care system [4,6-13].

A review of the evaluative research literature on foster care program outcomes in the United States shows that much is written about effectiveness and quality of performance. The evaluation studies in child welfare system have focused on "three goals of child welfare: safety, permanency, and well-being for children in foster care" [6]. However, this literature is mostly quantitative, with approaches using more quasi-experimental or experimental designs.

Only few studies of the multisystems partnership service delivery process have been conducted. Overall, the quality of services and programs for foster children and youth has been found to be poor to fair [14]. For example, The Institute for Educational Leadership [4] conducted an outcome study of the U.S. Department of Labor Foster Youth Demonstration Projects with the largest number of youth in foster care in five sites (California-Pasadena, South Central Los Angeles, 
Illinois-Chicago, Michigan-Detroit, New York - New York City, and Texas-Houston). That study, which used two site visits, phone interviews, and nine quarters of individual participant-level data, revealed poor collaboration between the workforce development system and the child welfare system - even though these entities' joint efforts are fundamental to the success of these projects. The evaluation study suggested that "a multisystem approach is needed, as no single agency can meet all needs. Partnerships are critical design elements for these types of programs and, as such, need to be part of the original program plans" [4].

In the late 1990s, state and local policymakers and practitioners began addressing the pressing need for reform of the child welfare system to shift from a single-system approach to a multiple-systems approach to delivering child welfare services. Equally importantly, increased attention has been given to understanding models of collaboration among multidisciplinary systems, to attempt to ascertain program success and improve quality-of-life outcomes for foster children and youth [15]. Nevertheless, although little is known about how multiple-system collaboration takes place in foster care programs at the local county level, few related studies have been conducted. For example, D'Emidio-Cason et al. [16] conducted 40 student interviews that collected 494 stories in a study of a California alcohol and drug program. An interesting finding using grounded theory was "meaning making" in understanding of the effects of substance use and its related outcomes. This is useful narrative information.

However, the D'Emidio-Cason and Brown study yielded no specific contextual understanding of the foster care system itself. Their 1999 study findings reveal a very limited, contextual point of view. As useful as this information is, it would be richer if other aspects of these children's services had been included as part of participant sampling. Small, single-agency/system evaluation research provides inadequate context for understanding the realities, complexities, and diversities of the child welfare system and how it affects children. Analyzing a single system of a child welfare program fails to adequately examine the complexities inherent in the overall child welfare system.

Parrish et al. [13] evaluated the educational outcomes for children in group homes in California. Their study asked about the nature of coordination between educational and noneducational agencies for services to children residing in foster group homes, factors affecting coordination, and the impact of current practices and procedures for interagency coordination on educational outcomes for children in group homes. Parrish et al. [13] used information from various multisystems resources relevant to foster group home processes, including state data analysis; surveys of staff at involved agencies; site visits; and interviews with students, statewide policy makers, and other interested parties. Findings suggest that despite some promising beginnings of change in California, a tremendous amount of work on interagency collaboration is needed to bolster educational outcomes for children in group homes. Given the information gained from this study, it is apparent that there is a lack of awareness of the crucial role of collaboration among the important agencies to meet the needs of the foster group home children. The agencies sometime see themselves in a positive light that is not shared by other agencies. In addition, the relevance of this study's findings is limited because the contextual complexity of interagency collaboration in foster group homes differs from that in foster care services, due to the different goals of each service arrangement [17].

Thornton, Okundaye, and Harrington (2007) studied the outcome of a training process in Maryland's subsidized guardianship project (GAP) using a true experimental design. Their study incorporated a multidisciplinary research team as a collaboration model for outcome evaluation of kinship foster care. The evaluative study suggests that the GAP outcomes were positive, including reduced length of stay for children in kinship care placements, because of effective training procedures in two different cohort groups. However, the Thornton et al. study failed to include detailed process data, as the researchers obtained direct participant evaluations relating to collaboration partners, including leaders who were not asked to formally evaluate it.

Green et al. [14] assessed the quality of group home services to foster youth in Alameda County, California. Data were collected at 32 group homes from 127 residents and 72 staff members in 20042005 , using 3 questionnaires developed by 14 youth evaluators. The authors noted the importance of individual contextual process for achieving positive outcomes with foster youth:

Both structural and process aspects of services influenced residents' satisfaction with services. However, only the process of care predicted changes in residents' developmental assets [emphasis added]. Statelevel regulatory agencies learned from these results that auditing only structural aspects of services was not sufficient to promote effective services. Focusing on these process aspects of service first should promote more change in outcomes and satisfaction for foster youth residing in group homes.

One related qualitative study of interagency collaboration was conducted by McLean [5], who examined barriers to multi-agency collaboration among key stakeholders to serve foster children with challenging behaviors in South Australia. Data were collected from a total of 92 respondents using a semi-structured interview about their collaborative practice, understanding, and management of school-age children with challenging behavior in out-of-home care. Findings drawn from thematic analysis suggested "several tensions inherent in such collaboration" [5] in three areas: (1) knowledge, attitudes, and frameworks for practice; (2) negotiation of systemic triangulation and power imbalances; and (3) inappropriate and ineffective resource allocation.

McLean's study focused only on general practice experiences of key collaborative stakeholders (in a broader sense) of multipleagency foster care services. This study failed to relate key stakeholders' experiences to implementation of a specific foster care program and broader interactional dynamic aspects of multisystems collaboration processes. This study also lacked data on incorporation of the strengths that various stakeholders brought to multisystem collaboration practice with foster children. More importantly, this study failed to appreciate the importance of dynamic interaction between research participants from a broader contextual point of view of the foster care service providers.

This article presents findings and recommendations from the first year of a two-year evaluation of the Local Interagency Network for Children and Family Services (LINCS) program, a part of the Shasta County Department of Social Services in northern California. Specifically, this report addresses organizational process effectiveness, and provides a descriptive evaluation of organizational redesign with focus on day-to-day operations, working relationships, and financial relationships. An additional focus is a comparison of how the county administered services to children in foster care prior to LINCS with how those services are delivered under the LINCS model. These findings and recommendations will give staff evidencebased guidance to improve service delivery in the LINCS program. This research approach is unique because it attempts to evaluate a foster care program by focusing on the qualitative experience and concerns of those within the multiple systems involved in collaborative child welfare practice efforts. This approach provides a much more accurate assessment of the overall process of the foster care program, using a broader contextual point of view that allows equally important multiple voices to be heard.

\section{Purpose and Research Questions}

A Multisystem Study of a Child Welfare Program in Northern California: This study undertook an independent evaluation of an 
innovative child welfare program in Northern California using as a model the Local Interagency Network for Children's Services (LINCS) program. The purpose of this evaluation was to establish whether the LINCS program has really implemented positive change and to allow identification of areas of strength and weakness so that the LINCS program can be made more effective. This formative evaluation focused more on the process than the outcome of the LINCS program. This formative evolution was important because at the time of the study the LINCS program was in the early stage of implementation. The study was designed to improve the change efforts, so this report focuses on describing what the LINCS program does and what happens during the service delivery process.

This evaluation (Phase I) assesses the quality and process of the LINCS program services to children in the foster care system relative to the desired outcomes or results of the program. To enhance the explanatory power of this research, designed to measure the effects of the LINCS program, the current descriptive evaluation was integrated with an impact study (Phase II). Because workingenvironment relationships are crucial to comprehending the quality and meaning of program efforts, this study examines issues of context and interorganizational linkages, including day-to day operations, financial relationships, and working relationships involved in the program.

\section{Statement of the Research Questions}

The focus of study was the following major research question:

- "How does the LINCS program handle the services to children in the foster care system in Shasta County?"

To answer this question, the following four subquestions were formulated:

- "How does the LINCS program handle the day-to-day operations of the agencies involved?"

- "How does the LINCS program handle the financial relationships of the agencies involved?"

- "How does the LINCS program handle the working relationships of the agencies involved?"

- "How did the County Department of Social Services administer services to children in foster care prior to LINCS and how are those services delivered under the current LINCS model?"

\section{Methodology}

Evaluating multisystem interventions is a difficult task. The simpler approach of focusing on a single subsystem is much easier and should be the initial effort of those new to the evaluation task. However, as noted in the literature review, analyzing a single subsystem will not produce the larger view of the agency context that is necessary for understanding the outcomes and impacts of child welfare services.

Many program evaluations utilize a quantitative outcome approach, such as exploratory, descriptive, descriptive, and/or experimental designs. This is true of foster care program outcome evaluative studies as well: They most often employ deductive procedures in assessing the success of foster care programs. In contrast, the inductive qualitative approach utilized in this study drew out personal and collective experiences of various foster care service providers. Understanding these experiences is important because the experiences critically affect the dynamics of the interacting agencies and problems will critically affect the children in care. It is very important to understand how all principal actors personally experience: (1) specific processes and their results, (2) positive experiences and their sources, (3) problems encountered and possible solutions, and (4) the interactive dynamics of the multisystem environment.

"Program evaluation is a practical endeavor, not an academic exercise and not an attempt to build theory or necessarily to develop social science knowledge" [18]. An innovative model of foster care service delivery is primarily an effort to influence the knowledge, value orientation, and behavior of various practitioners in the foster care system. Thus, it is important to achieve an in-depth understanding of the meaning revealed through daily practices and interactions of foster care service providers. The LINCS program was designed to implement a new interagency approach that included and brought together a wide range of professions and disciplines in a rural community. Extensive focus-group interview data regarding the processes of the LINCS program were needed for effective program outcome evaluation.

A qualitative inductive approach using focus groups and thematic analysis was considered appropriate because of the importance of interaction between participants to the exploratory and descriptive nature of the research knowledge in the context of the multisystems collaboration processes of LINCS program delivery. In particular, this study tried to maximize interaction among participants. As Jenny Kitzinger [19] emphasizes, the methodology of focus groups is unique, considering "the research session as a forum within which ideas could be clarified rather than simply as a 'natural event' [that] influenced the ways in which we chose to run the groups" (p. 4).

Discussions on the design of this two-phase study began early in the spring of 2001 between the director of the Department of Social Services, the LINCS program manager, several staff members, and the author as principal researcher. For purposes of this study, the decision was made to combine focus group data with fiscal information provided by the Department of Social Services' fiscal analyst.

Eleven focus groups, ranging in size from 4 to 11 participants, were conducted; all the focus groups met throughout a four-month period. Each focus group met for two to four hours. The group members were given a list of questions to guide their discussions. The sessions were audiotaped and transcribed for purposes of analysis.

Study participants were assigned to groups based on their role in the LINCS program. Separate focus groups were organized within each of the following relevant categories:

1. Management levels of services (one group of higher-level managers from various departments within the LINCS program, one of mid-level managers, and one of lower-level managers).

2. Specialty teams for the children and family services workers (one from the Local Interagency Family Treatment Team [LIFTT], one from treatment, and one from placement).

3. Participation types (one group from the Children's Service Division team of line workers, one from the Children's Service Division team of supervisors, and one of upper-level managers and key community leaders and community-based service providers).

4. Relationship positions (one group of foster parents and one from California Youth Connection [CYC]).

Each focus group contained subjects in similar positions within the structure of the program. For example, one group was made up of mid-level managers from five different departments within the LINCS program. This composition allowed for between-group comparisons, plus identification of issues and concerns by management level, specialty team, participation type, and relationship position. However, certain within group comparisons could also be made based on the data produced by the focus groups. Even though the groups were purposefully designed to be homogeneous as to position within the structure, the group members were still heterogeneous in department membership and professional background. These factors are related to the differences in perspectives within LINCS that emerged as important findings in this research.

Before beginning the focus-group discussion, each participant gave his or her informed consent to participate in this study. Each participant then completed an anonymous questionnaire that asked for demographic information. Three focus groups CYC youth, foster parents, and Children's Services Division supervisors were also asked 
to rate the service delivery system both before LINCS and during LINCS. The members of these three focus groups were asked to indicate their opinion of the effectiveness of both the prior and current programs on a continuum from "very effective" to "not very effective." They were then asked to rate the two programs on a similar continuum that ranged from "few negative effects" to "many negative effects."

\section{Procedures for Analyzing Data}

The qualitative findings of this study were generated using thematic analysis procedure. According to DePoy et al. [20], "thematic analysis involves examining data for emergent patterns and themes ... . Emergent themes are identified and labeled and exemplars of each used" (p. 239). The thematic analysis in this study yielded narrative data drawn from participants' discussion, with emphasis on day-to day operations, financial relationships, working relationships, and the comparison of service delivery under the prior program and service delivery under the current LINCS program.

A thorough analysis based on repeated examination of the full set of transcripts was undertaken with the goal of explicating and understanding the major themes and answering the research questions stated earlier. Although all groups addressed the guide questions they were given, additional topics emerged consistently in many focus groups during the discussions. Those topics were also included in the analysis based on three factors: (1) How many groups mentioned the topic; (2) how many people within each of these groups mentioned the topic; and (3) how much energy and enthusiasm the topic generated among the participants.

One additional set of qualitative data was analyzed during this research. As noted earlier, three focus groups (CYC youth, foster parents, and Children's Services Division supervisors) were asked to rate the effectiveness and negative effects of the previous and current service delivery systems. Their ratings allowed us to compare these participants' opinions of the two systems.

\section{Limitations of the Study}

Because it is based on qualitative data from focus groups, this study does not offer precise statistical statements about the population under study. Its strength is that it promotes in-depth understanding and yields illustrations of the topics under study. Observing focus groups' discussions does not permit analytic interpretation of data; rather, it provides important insights into the participants' perception of the new process of foster care services delivery.

\section{Key Findings}

This section summarizes the salient findings that emerged from the discussions of the 11 focus groups. A content analysis was performed utilizing the transcriptions of the audiotapes recorded during the focus group meetings. The points included here emerged in one or more of the focus groups. Each of the focus groups had unique opinions about the LINCS program based on the participants' unique position within that program. In fact, the focus groups were deliberately formed such that these unique perspectives could be voiced. For example, the foster parents had a perspective very different from that of the upper managers. For the purposes of this study, each focus group's opinion was considered equally valuable and significant. Therefore, if the members within a group agreed on a certain point, that point was included in the key findings regardless of whether the same point was raised in other groups. In other words, the points that follow resulted from intragroup rather than intergroup agreement.

Key findings are organized into the four research subquestions specified earlier in this report. They involve:

- The day-to-day operations of the LINCS program (discussed by all the focus groups except the CYC youth).

- The financial relationships of the agencies involved in the LINCS program (only the three focus groups of directors, middle managers, and significant others discussed the financial relationships of the agencies involved in LINCS, as the remaining groups were not directly involved with this issue).

- The working relationships of the agencies involved in the LINCS program (discussed by all the focus groups except the CYC youth).

- Comparison of the foster care services delivery system under the prior program and under the LINCS program (the only issue discussed by the CYC youth group).

\section{Day-to-Day Operations of the LINCS Program}

1. What is your view or perspective on the LINCS program? Or what are the underlying principles and values of the LINCS program?

The strengths of the LINCS program identified by the focus groups include:

- Emphasis on interactions and learning.

- Better understanding of foster children's lives.

- Trust building and sharing.

- "User-friendly service network" for all clientele.

- Improved accessibility to services by co-location/one-stop shopping center for all services and staff.

- Good fit with social work practice values (e.g., optimistic, positive view).

- Multiagency team approach.

- Mutual benefits of collaboration and coordination among agencies involved in the program.

- $\quad$ Strengths-based approach to families.

Most of the groups had predominantly positive comments about the LINCS program. However, two or three of the groups focused more on weaknesses. The negative features of the LINCS program identified by these groups include:

- A "separatist philosophy" creating a split between the LINCS program and the Children's Service Division (a comment repeated often by line workers at Child Protective Services [CPS]).

- Frustration stemming from poor collaboration and poor coordination between the LINCS program and the Children's Service Division.

- A lack of forethought about sufficient physical space.

- Lack of flexibility of staff working as a team.

- Weak connection with outsider service providers (e.g., difficulties getting phone calls in to LINCS staff).

2. Please describe how your department's or agency's or unit's mission, goals, and objectives relate to the whole LINCS program's mission, goals, and objectives.

Overall, all focus groups described these relationships very generally rather than specifically (i.e., a specific extent or level of expectation of the service outcomes). Again, there were clear differences between the focus groups. Some groups described positive interconnections between the two, whereas others described less positive ones.

Generally, the focus groups of upper managers, middle managers, and line staff described more positive connections among mission, goals, and objectives than did outsiders (foster parents, CYC youth, etc.). However, all focus groups had difficulties making a strong connection between their departments, agencies, or units and the broader LINCS program as a whole. The descriptions were vague and narrowly focused, and lacked a broader conceptual design of the LINCS program. The following summarizes the relations agreed upon within the groups as they identified the interconnections between the departments, units, or teams and LINCS:

- Shared vision and goals that mutually benefit agencies.

- Shared orientation to achieve the best possible outcomes for foster 
children and families served (i.e., "improving the life of people in Shasta County" and ultimately reunification of the children with their families).

- Both comply with state rules and regulations.

- Co-location helps unify separate units into a single, cohesive program.

- Encouragement of interagency team collaboration. Both promote fine tuning of agencies' working together (e.g., allowing a continuum of services from the beginning of involvement with the families, merging the short-term goal of a drug and alcohol program into the long-term goal of the LINCS program, connecting the LINCS program with a larger systems of care, bringing all related parts together).

- Both promote flexibility (e.g., being flexible with paperwork and restrictions set by different disciplines).

- Making the services a continuum between LINCS and CPS.

- Both emphasize coordination of services and resources.

- Both assist staff in providing more comprehensive services that focus on the strengths of the families and the children in a holistic approach.

- Both emphasize making recommendations to administrators about program change, developments, and need in the community. In that way, they both support mid-level managers to act as an advisory group and an oversight group for the LINCS program (e.g., planning).

- Both create "seamless" services (e.g., less rigid boundaries between the units of treatment placement or between the departments of probation and social services).

Several groups described weak connections between their team and the LINCS program, which included:

- Limited shared understanding of the operations between the LINCS program and the Children's Services Division (CSD).

- Difficulties in communicating about placement decisions due to the physical split between LINCS and CSD.

- Two conflicting philosophical points of views on the best interest of a child (LINCS emphasis on reunification vs. CSD on safety or protection).

- Inconsistency of services provided to children who returned home.

3. How do your team members from different disciplines interact during day-to-day activities?

The focus groups (except for the CYC group) discussed how their day-to-day activities involved both informal and formal interactions with team members.

Informal interactions involved relaxed contacts for seeking information on cases, services, and programs. They included:

- Workers having brief conversations about cases while passing in the hallway (e.g., they might discuss ongoing cases and share what each person's department is doing).

- Brief contacts to change schedules.

- Stress management with humor, laughs, and jokes.

- Support and fellowship for one another

- Formal interactions included:

- Regularly scheduled staff meetings.

- Multidisciplinary team meetings to share interagency information and/or share outcome information, especially about particular families (i.e., sharing success case stories).

- Relevant agencies meeting to coordinate services linkages (e.g., coordination of medical service appointment for doctors and nurses, medication issues with the juvenile court action, foster children crisis management, education about programs and procedures, etc.).
4. What things can go wrong in collaboration efforts with people in the LINCS program? How are these identified and corrected?

Overall, the forces inhibiting collaboration were identified and described as:

- Communication errors in the separate Child Welfare Services (CMS)/Case Management System (CMS) database (e.g., the public health nurses and the education people may send the same foster parent different information).

- Conflicting emphasis on foster children's placement issues between education and social services (e.g., from an education perspective, educational placement is not the same as a social services placement, which often just moves children from school A to school B).

- Miscommunication. Some group members noted miscommunication between various agencies because of differing methods and cultures.

- Poor communication between CSD and the LINCS line workers.

- Poor collaboration between CSD and mental health staff at LINCS.

- Confidentiality policies and laws.

- Conflicting values between professionalism and bureaucratic demands, especially for CSD staff.

Some of the focus groups described conflict-resolution processes, including:

- Move issues through hierarchy of authority when personal communication does not work.

- Continue open and clear communication efforts, constantly sharing information until agreement is reached.

- Communicate using a strengths perspective rather than a deficit perspective.

- Use announcements and meetings.

- Undertake team-building processes.

\section{Financial Relationships of the Agencies Involved in the LINCS} Program

Only the three focus groups comprised of directors, middle managers, and significant others (former directors, community-based service contractors, county board of supervisors members, etc.) discussed the following questions.

1. Do financial relationships exist among the agencies involved in the LINCS program? Are there any official interagency agreements on who pays for what?

Financial relationships among the agencies involved in the LINCS program, including agreements on who pays for what, were described as follows:

- No "official" or "formal" interagency agreements on covering costs exist. The first step of LINCS emphasized "working together first" without written or formalized financial agreements.

- The departments do make verbal agreements on covering costs while they work together. These include:

$\diamond \quad$ Reallocations that function to share costs

- $\quad$ All social services operating expenses (e.g., information systems, travel, and training)

- Space allocation as it relates to rent

- $\quad$ Staff allocation

$\diamond \quad$ Each department pays its staff's gas and travel costs.

$\diamond \quad$ The county covers $50 \%$ of nonreimbursed expenses with federal pass-through funds.

- Although the nature of the LINCS program made billing and cost-sharing more labor intensive than in the past, the benefits of the program, especially for the clients, made it worth it. 
- The budgets and expenditures of some departments' individual programs changed little despite their evolution from independent to interdependent with the advent of the LINCS program.

- Much creative energy went into figuring out how to create the program and then how to work the finances.

- Trust is an integral requirement for sharing costs of services and operating expenses.

- A fiscally conservative approach to foster children's welfare among the Board of Supervisors and department heads (i.e., keeping foster children in the system for less time) co-exists with the standing formal agreement on a shared vision of better outcomes for foster children.

- Fiscal policies were described as resulting in a more professional approach. Some felt more respected and provided for in the LINCS program. LINCS created an environment in which each department's professional roles and services became more prominent.

2. What are funding sources that your department or other agencies use for supporting the LINCS program?

Focus groups reported the use of various funding means, which included federal, state, and county sources.

Federal funds include:

- Child welfare services (CWS) allocation (support staff, equipment, rent, cars, training, etc.).

- Systems-of-care funds from the Mental Health Department (fund staff, resources, mental health services).

- The Early and Periodic Screening, Diagnostic and Treatment (EPSDT) (a part of systems-of-care dollars) to provide services for youth with lower risk.

- EPSDT Medi-Cal funding (through the Mental Health Department's reimbursement process) for a Social Services children's services manager who is licensed and qualified to allocate time to the activity, thereby freeing up some Department of Social Services (DSS) Child Welfare Services allocation money.

- State Children's Health Insurance Program (SCHIP) (e.g., provide treatment services to children who do not have medical insurance or coverage).

- $\quad$ SB 933 allocation (funding for travel of probation officer visits to group and foster homes).

- Medi-Cal, Title XIX (for both treatment services and communitybased contract agencies with crisis intervention services).

- Temporary Assistance to Needy Families (TANF) and Title IV-E funds from Probation Division for staff assigned from that area.

- Medi-Cal billing for specialty mental health services provided on a fee-for-service basis.

- Child Health and Disability Prevention (CHDP) foster care fund (federal social service monies allocated by the state to the Children's Medical Services branch of the Department of Health Services).

State funds include:

- SB 163 for children at risk, to keep them in their homes and the community rather than being placed in a group home.

- SB 933 allocation to cover travel costs for probation officer visits to group and foster homes.

- CHDP foster care fund (social services monies allocated at the state level to the Children's Medical Services branch (e.g., support staff, equipment, rent, cars, training, etc.).

- Standards and Training for Correction allocations from the State Board of Correction for all training expenses for probation officers.

- Foster Youth Services funding contributed by the California Department of Education/Office of Education.
County funds include:

- Public health realignment funds for $7.5 \%$ public health staff cost (and $92.5 \%$ of public health staff cost paid by Social Services).

- Social Services realignment funds and county general funds that match state and federal CWS allocations.

3. What problems are associated with fiscal issues in the LINCS program?

Overall, the participants stated that there were no overwhelming fiscal issues and no conflict among departments on spending specific monies. However, while they were not viewed as overwhelming, the groups did note some fiscal problems. Perceptions of the fiscal issues addressed in the groups include:

- Complications in figuring out what staff can spend on children and families with multiple department involvement (e.g., a family has two probation youngsters and two CPS youngsters).

- Lack of understanding of numerous applications for funding, making it difficult for line workers to complete the appropriate request forms for service and resources.

- Complexity of mixed categorical and noncategorical funding with focus on better services. LINCS program funds are not $100 \%$ blended and may never be. That requires workers to deal with mixed-funding issues almost daily.

- Lack of formal agreement regarding the shared fiscal responsibilities of the various departments collaborating in LINCS.

- Inadequate funding for filling positions (e.g., two directors, supervisors, etc.).

- Budget cuts resulting in tighter funds for all the various agencies.

- Increased personnel costs coupled with decreased program budgets.

- Realignment as the state's plan for funding health and welfare programs. The state lowered its contribution and demanded more categorical funding for the services covered by LINCS.

- The departments get allocations that do not cover even half of their total budgets.

- The unstable California economy-beyond the control of the county and LINCS departments-affects the LINCS budget through realignment revenue fluctuations.

\section{Working Relationship}

1. What factors make collaborative efforts work in the LINCS program?

Effective collaborative factors included:

- Shared vision that the best interests of the children are served by agencies working together.

- Commitment of directors, middle managers, and line staff.

- Administrative leadership.

- Increased trust.

- Shared responsibility for clients.

- Co-location of staff and services.

2. Please describe your professional relationships in the LINCS program. And, how do you feel about relationships with your co-workers? For example, are these interactions welcomed?

Most participants did not experience critical problems with their working relationships. However, some noted negative interactions that occur periodically. Specifically, focus groups of staff from LIFTT and within LINCS (line workers, supervisors, etc.) described their interactions with each other more positively than did those focus groups of people outside LINCS (foster parents, line workers at Children's Services, CYC youth). The latter had more negative comments about their interactions with the LINCS personnel. In addition, upper-level administrators (i.e., directors) and line workers 
experienced more positive relationships with co-workers than did middle managers and supervisors.

Positive interactions that occurred repeatedly included:

- $\quad$ Being welcomed, valued, and respected (e.g., staff are treated as important, valued, and an integral part of LINCS; staff respect each other for their expertise).

- Being supportive.

- Blending of different professional cultures because each is a part of the conceptual design requiring multiple professional focus on children (integrating the different emphases of mental health, social services, probation, etc.).

- Hierarchical support of leaders' shared vision. Participants in the group who raised this point felt that it was an incredibly difficult task to combine the disciplines and agencies the way LINCS has (e.g., program manager and staff offered their support for the current leadership in attempting to get all aspects of the program working together).

- Shared vision.

- Common commitment to the LINCS goal of providing coordinated services.

- Learning from each other.

- Co-construction of solution with families.

- Knowing the staff from different departments personally. Preconceived notions and stereotypes about staff from different departments were dissipated because of their relationships with each other. Staff get to know their team members as individuals and appreciate their professional expertise in making the team work for a family.

- Learning about the other departments and programs (e.g., social services learned about the mental health department's reorganization).

- Working closely as a team to coordinate the child welfare services program and contract services, and handle many issues together.

- Growing trust of staff from different departments and agencies.

- Maintaining dual relationships simultaneously with home departments and LINCS team.

- History of collaboration among department directors (e.g., collaboration between department directors of social services, probation, and mental health has existed for years).

- History of companionship among all levels of staff.

- LINCS structure that requires relationships among lower, middle, and upper managers and provides formal venues for interaction (e.g., LINCS supervisors interact closely all the time and meet every Wednesday morning with supervisors at Children's Services and mid-level managers as a large group; mid-level managers and supervisors at Children and Family Services meet once a month).

- $\quad$ LINCS structural design that includes joint decision making (e.g., supervisors, middle managers, and cabinet solve problems together and have joint input at the different agencies or programs).

Negative interactions included:

- Disparate levels of directors' commitment to the LINCS program and the program goals of coordinated services to children and families. Some commitments appear strong whereas others are weak.

- $\quad$ Some staff, mostly male, experienced personal difficulty with collaborative team approach due to individualistic value system and history of working alone.

- $\quad$ LINCS program manager faces multiple challenges in dealing fairly with the different mechanisms of four departments within LINCS (e.g., different polices of four departments for requesting time off, dress code, different pay levels, etc.).

- Not all levels of personnel from different departments are co-located; this situation limits vertical interactions and networking among them (e.g., the probation director has a connection only to placement staff from probation, not to staff from public or mental health).

- Line workers often feel overwhelmed (e.g., many things to remember and a large number of contacts to make).

- Line workers often feel that their jobs are unstructured chaos (e.g., they are thrown together and left to figure things out by themselves).

- Disruption in administrative leadership causes confusion among staff (especially line staff) and loss of LINCS vision.

- Conflicting loyalties resulting from dual membership in team and in mother agency, especially for new staff members.

- Resentment on the part of staff at Children's Services (CS) at being left out of the case management process by LINCS staff (CS participants repeated often that they are rarely included in the management process. They are approached only when something has gone wrong with a particular family or child, but because of their previous exclusion, they do not have the background knowledge to handle the situation quickly or effectively).

- $\quad$ Line staff at CS feel undervalued. They perceive that units in LINCS do not view CS staff as being at the same level. "I am treated as a professional but my services, requests, or wants are secondary to what is going at LINCS."

- The growth of LINCS has resulted in the hiring of new LINCS workers who know nothing about the background and work history of the staff at CS, especially the senior staff.

- CS workers are distraught at the wide split between CS and LINCS and the different priorities of the two (i.e., protecting children in CS versus supporting adoption or reunification in LINCS).

- Poor communication between LINCS and CS.

- Distrust and doubt. The physical separation and relational split between LINCS and CS have also led CS workers to develop feelings of distrust of LINCS in regard to budget, individual program assessment, and worker evaluation.

- Staff at CS cite increased bureaucracy, inconsistent procedures, and complexity of decision-making process for providing services since the implementation of the LINCS program; they say the system is not as productive as before.

- CS supervisors cited different bureaucratic micromanagement in LINCS (e.g., staff from mental health and probation have much stricter guidelines on where their money comes from, so staff have to do time studies every 15 minutes in LINCS).

In addition to staff and agency comments, some problems related to foster parents' interactions surfaced:

- Many foster parents are confused (e.g., different philosophies between LINCS and CS, return children home at all costs versus keep children removed; information about infant mental health; and location of a new adoption worker for LINCS in the CS building).

- Foster parents have not been completely informed about all services at LINCS.

- Some foster parents feel that staff treat foster parents, birth parents, and adoptive parents differently (e.g., some staff favor foster parents and others birth parents).

- Foster parents feel that LINCS interactions are more formal, in contrast to CS, which is more relaxed (e.g., stop at the LINCS front door; sharing too much information).

- Foster parents are not contacted when the biological parents cancel visits.

- Foster parents perceived a deficit-oriented approach to foster children remaining in care (e.g., not seeing children's problem from a larger chronic community problem viewpoint). 
- A few foster parents feel they are not protected by staff in LINCS, especially when biological parents drop their kids off.

- The placement committee's approval process results in difficulties with processing a placement team's decision on cases.

3. What is future plan for involving other teams or units, organizations, and agencies with the LINCS program?

Focus-group members varied on their ideas about plans for the LINCS program. Some of the group participants were not aware of any plans to add to the existing departments, whereas others had plans for further development. Future plans of the LINCS program that were known to participants included:

- Expansion of interagency staff that is more solution focused (i.e., front end of child welfare system).

- Institution of a formal child-focused, family-centered approach (i.e., a family conference where the family, their support people, agency providers, and interagency team work together to make a plan, and if the plan fits, then the family does not necessarily have to come into the foster care system).
- Incorporation of more private organizations in the collaborative effort.

- Becoming a future model of probation (e.g., expanding some of SB 163 "Wraparound" designs).

- Broadening the interagency programming on the front end of the foster care system by using more interagency collaborative efforts for prevention and early intervention (e.g., social services, part of probation).

- An increased role for private, nonprofit agencies in service delivery.

\section{Comparison of Foster Care Services Delivery in the LINCS Program and the Prior Program}

Service delivery involves the detailed arrangements of programs, staffing, facilities, funding, and administrative management that are considered the unique features of the foster care services in the LINCS program and the prior program in Shasta County. The following questions were discussed to identify major differences in service delivery between the two programs. Highlights of the comparisons of foster care services delivery in the LINCS program and the prior program are presented in Table 1.

\begin{tabular}{|c|c|c|}
\hline & Preintegration Practice & Postintegration Practice \\
\hline Nature of Program & $\begin{array}{l}\text { Traditional Child Welfare Services } \\
\text { (CWS) system }\end{array}$ & $\begin{array}{l}\text { Wraparound systems of care, planning } \\
\text { model. A family-focused, strengths- } \\
\text { based program in which intensive and } \\
\text { comprehensive social, mental health, } \\
\text { and health services are "wrapped" } \\
\text { around children and their families } \\
\text { (biological, foster, and/or adoptive } \\
\text { families) to reinforce natural family } \\
\text { network supports and to continue that } \\
\text { relationship over time. }\end{array}$ \\
\hline Target Population & All children in CWS & $\begin{array}{l}\text { All children in treatment (including } \\
\text { Family Maintenance, Family } \\
\text { Reunification, Permanent Placement). } \\
\text { Once adjudicated in court, case goes } \\
\text { to LINCS. }\end{array}$ \\
\hline Referral for Services & $\begin{array}{l}\text { CPS serves as "gateway" to services. } \\
\text { Referral for services only for } \\
\text { substantiated cases through court- } \\
\text { ordered treatment plan. }\end{array}$ & $\begin{array}{l}\text { Expanded easier, friendly access to } \\
\text { services through multiple departments' } \\
\text { collaboration and community supports. }\end{array}$ \\
\hline Location of Services & $\begin{array}{l}\text { Many, separate locations } \\
\text { (decentralization of services); Children } \\
\text { and Family Services in one location. }\end{array}$ & $\begin{array}{l}\text { One-stop center for Social Services, } \\
\text { Mental Health, Physical Health, } \\
\text { Probation, Alcohol/Drug, County } \\
\text { Office of Education depending on } \\
\text { public transportation (centralization of } \\
\text { services). } \\
\text { CPS in two different locations. }\end{array}$ \\
\hline Service Linkage & $\begin{array}{l}\text { Single, individual working relationship } \\
\text { between existing departments, } \\
\text { agencies, and organizations in } \\
\text { separate, fragmented services network. }\end{array}$ & $\begin{array}{l}\text { Collective working relationships } \\
\text { between existing departments, } \\
\text { agencies, and organizations in the } \\
\text { wider, closer, co-located social service } \\
\text { network. }\end{array}$ \\
\hline Investigation & $\begin{array}{l}\text { CPS leads investigation, sometimes in } \\
\text { tandem with law enforcement. }\end{array}$ & No change from prior practice. \\
\hline Process of Decision-making on Case & $\begin{array}{l}\text { Social worker's individual discretion } \\
\text { was high in decision-making on case. }\end{array}$ & $\begin{array}{l}\text { Social worker's individual discretion } \\
\text { is reduced and multiple systems } \\
\text { participate in the decision- making } \\
\text { process. Improved family and } \\
\text { children's participation in treatment } \\
\text { planning and decision-making process. }\end{array}$ \\
\hline
\end{tabular}




\begin{tabular}{|l|l|l|}
\hline Responsibility for Child Protection & $\begin{array}{l}\text { CPS, Mental Health, and probation } \\
\text { are individually responsible. }\end{array}$ & $\begin{array}{l}\text { Shared responsibility with other } \\
\text { public agencies, community partners, } \\
\text { schools, families, and their extended } \\
\text { support networks. Joint case planning } \\
\text { and case management across existing } \\
\text { agencies and programs. }\end{array}$ \\
\hline Structural Design of Integration & $\begin{array}{l}\text { Single-agency model. } \\
\text { Bureaucratic structure model. }\end{array}$ & $\begin{array}{l}\text { "Vertical integration" model to } \\
\text { reorganize existing agencies and } \\
\text { programs by co-location of staff and } \\
\text { services at lower-level management } \\
\text { (interagency supervisor team) and } \\
\text { line workers (treatment and placement } \\
\text { teams). } \\
\text { "Horizontal integration" model to link } \\
\text { existing agencies and programs with } \\
\text { steering committee at the mid and } \\
\text { upper management levels. }\end{array}$ \\
\hline $\begin{array}{l}\text { Funding Strategy } \\
\text { Method to Prove Effectiveness of } \\
\text { The Services/Program }\end{array}$ & $\begin{array}{l}\text { Unknown Overview of Key Changes from Preintegration Practice to Postintegration Practice } \\
\text { practice. }\end{array}$ \\
\hline
\end{tabular}

1. How was the LINCS program introduced into Shasta County? What were the political mechanisms by which the LINCS program was initiated and maintained?

There was significant agreement among focus-group participants on how the LINCS program was introduced to the Shasta County foster care delivery system. Participants described the following chain of events: Shasta County has a relatively long history of supporting integrated services for children and families; this has been one of the strongest prevailing concepts in foster care services. In 1966, the county took another step toward greater integration of foster care services when the Local Interagency Family Treatment Team began a collaborative approach under the leadership of Lynne Jones, program manager of LIFTT. LIFTT brought together a team of professionals from various county agencies, including alcohol and drug programs, Children's Protective Services, Community Mental Health, Juvenile Probation, and the Office of Education. Demonstrated success of the LIFFT program, in combination with committed leadership, particularly from the former Department of Social Services director, convinced the Board of Supervisors to approve a reorganization of Children's Services in June 1999 and the Local Interagency Network for Family and Children and Family (LINCS) was born. By June 2000, LINCS held the promise of solutions to some of the most universal problems in human service delivery: how to adequately serve the comprehensive needs of children and families; how to prevent duplication of effort; how to reduce fragmentation; how to gather comprehensive data; how to become more accountable; and how to create a seamless service delivery system that has fewer barriers for the consumer to overcome.

2. How has the LINCS program changed the foster children services delivery system in Shasta County?

Overall, participants believed that moving to the LINCS program was an important step in the right direction. However, there were significant differences in perception regarding the effectiveness of service delivery under the prior program and the LINCS program. Specifically, staff from within the LINCS program (e.g., focus groups of directors, middle managers, supervisors, and line workers) described the service delivery of LINCS program as more effective than the earlier program with fewer negative results. In contrast, those from outside the LINCS program (e.g., focus groups of Children's
Services Division line workers, foster parents, and CYC youth) had more varied opinions. Most agreed that LINCS was more effective; however, others were less complimentary. They either believed there were no differences between the two programs in effectiveness or negative results, or that LINCS was less effective than the prior program.

As you read the following comparisons of the perceptions of the two service delivery systems, keep in mind that not all participants characterized the two systems in the same way. The items included in this report are not reflective of total and unanimous agreement. Rather, each point made about the prior program and the LINCS program was described as significant by all the participants in at least one focus group. This also reflects the unique position and experience of each of the focus groups related to different levels of management and service linkage and LINCS program.

As described by the participants during the focus groups, the major characteristics of the prior program included:

- Focus on deficits and problems.

- Single organizational structure, such as the Department of Social Services Division of Children and Family Services.

- Major programs and services, such as Child Protective Services and Foster Care Services.

- Other services in many separate locations.

- Parental power limited by state supervision.

The major characteristics of the LINCS Program were described as:

- Focus on family strengths and solutions to achieve desired outcomes of safety, permanence, and well-being for children in the foster care system.

- Some level of service linkage through cooperation, coordination, collaboration, and integration.

- Shared vision based on related departmental goals and objectives.

- Shared responsibilities (e.g., sharing costs) and outcomes for the foster children in Social Services.

- Increased accountability

- Systems of "checks-and-balances" for both workers and disciplines. 
- Increased services for youth from Social Services and Juvenile Probation. The services are immediately accessible, flexible, and comprehensive, especially those provided by public health nurses, therapists, caseworkers, alcohol and drug counselors, education specialists, and psychiatrists.

- Bifurcation of the DSS division into two separate parts:

$\diamond \quad$ Children's Services Division with Emergency Response; Investigations.

$\diamond \quad$ Court; Foster Care Licensing; and Adoptions.

- LINCS program, having two key interagency teams: Treatment and Placement (LIFTT is not included here because there is some disagreement as to whether LIFTT is part of LINCS; see discussion infra).

- Both "vertical" and "horizontal" integration of organizational structure. Vertical integration refers to co-locating line workers and services into a "one-stop shopping" service delivery center. This was a bottom-up reorganization into a more communitybased, consumer-friendly delivery system that involved staff from Social Services, Mental Health, Alcohol and Drug, Public Health, Juvenile and Adult Probation, Education, community-based partner organizations, foster youth, foster parent associations, and parent partners. Horizontal integration refers to the development of interagency oversight by mid-level managers' committed leadership.

Participants raised many issues and concerns about the LINCS program, which included:

- Increased complexity of the organizational process (e.g., more layers and chains of decisionmaking) makes problem resolution more challenging and costly.

- Lack of service continuity between the Children Services Division and the LINCS program after bifurcation.

- Philosophical differences between LINCS and Children Services Division lead to premature reunification of children and families.

- More children came back to the child welfare system. Some CPS staff suggested that there are more youth coming back into the system because "we are being premature in sending these kids home."

- Children are being reunited with families before their treatment plans are completed.

- Lack of contact between foster parents and biological parents.

- Difficulties in communication between consumers (foster youth and foster parents) and LINCS staff.

3. Do you see any difference in how foster children are viewed and treated in the LINCS program compared to the prior program?

The focus groups varied on their opinion about how the two programs viewed and treated children. Some groups saw more positive changes in the movement from CPS to LINCS, and others saw more negative changes. Following is a summary of changes agreed upon within the groups.

The positive changes identified in the movement from CPS to LINCS include:

- A new "empowerment approach" (e.g., foster youths' voices heard more, increased participation in treatment planning as an equal partner in a team, etc.).

- Multidisciplinary, holistic view of children from strengthsbased approach.

- New treatment of foster youth as consumers of a service rather than as property of a particular department.

- Foster children go back home faster.

- More foster children are brought back to their home county.

- Treatment with respect (e.g., listening to foster children and their families).
- More positive image of foster children, rather than being stereotyped as "bad kids."

- Better and increased number of contacts and relationship with natural families, foster parents, and community.

- Foster children's increased sense of belonging to the community and ownership of their own lives.

The negative changes identified in the move from CPS to LINCS include:

- Discontinuity of services between CPS and the LINCS program.

- Less social work connection with the children.

- Less close, less intensive monitoring process in reunification cases.

- Less focus on individualism with children.

- Persistent negative attitudes about foster children on the part of a few workers.

- Lack of knowledge about how to access and use services for foster children and foster families.

4. Are there organizational barriers to growth and development in the LINCS program? If you had a magic wand, what would you change about services to foster children in the LINCS program?

Suggestions for improving the LINCS program included:

- Improving the willingness and flexibility of different disciplines to come together and work for LINCS.

- Finding solutions to financial problems that are the most daunting barrier to the growth and development of LINCS (e.g., lack of sufficient and stable sources of state and federal funding). Yearto-year budget problems limit long-term planning and stability.

- Increasing the scope and size of the current LINCS program by expanding services to those outside of the foster system, with more specialized segments of the LINCS program to target specific behaviors exhibited by clients.

- Increasing the number of employees to better meet the needs of those the agency currently serves.

- Mitigating language and cultural barriers, resulting from colocation of staff from different disciplines, that lead to general confusion, both politically and organizationally.

- Increasing administrative management leadership and support.

- Increasing service coordination from the beginning to the end of services.

\section{Discussion}

This section focuses on strengths, recommendations, and areas for LINCS program improvement. Though these points are specific to the LINCS program, many of them are generalizable or applicable to foster care service delivery systems in general, and there are implications for knowledge to be gained from qualitative process evaluation research on foster care programs.

\section{Strengths}

Identified problems not withstanding, LINCS is an impressive program that has made significant developmental strides in a relatively short period of time. It enjoyed unusual and enviable support from the highest levels of county administration, the professional community, and local residents. It has painstakingly found a service market "niche" that is consistent with the needs of the region and the interests of the service sector and at-risk foster children and families.

The commitment and enthusiasm of the entire staff are noteworthy. This not only suggests that the preceding "niche" observation is accurate, but also that the staff are doing an effective job of providing seamless services for foster children and families while remaining uniquely excited about their helping process. The common mission of a seamless, strengths-based, family-driven system, the collaboration across departments and community agencies, and the joint decisionmaking in the LINCS program — all justifiably lauded 
by its passionate staff - are indeed impressive.

Furthermore, this has been accomplished without the need for major governmental restructuring or creation of another layer of bureaucratic response. This suggests that the staff involved are particularly talented and committed.

\section{Recommendations and Areas for Improvement}

The following recommendations were drawn from analysis of the perceptions of the 11 focus groups' participants on the organizational redesign in the child protective services delivery system.

1. Development of an overarching conceptual design requires immediate attention.

There was very strong concern from the entire staff, especially upper-level and mid-level managers, regarding the nature of core conceptual design in LINCS. These administrators experienced very serious challenges and conflicts. There was also a serious question from LIFTT staff members about whether or not LIFTT is under the LINCS umbrella.

- It is recommended that an overarching conceptual design be developed.

The interagency collaboration perspective would be an appropriate conceptual model, composed of two links: horizontal and vertical. The horizontal linkage deals with structure and function within core service units and teams. It conceptualizes how key service units and teams within LINCS (e.g., treatment unit, placement unit, adoption unit, and court unit) relate to and support each other. The vertical linkage deals with structure and function between departments and agencies. It conceptualizes how to integrate separate departments and agencies (e.g., social services, mental health, probation, and public health). These horizontal and vertical linkages would make the helping relationship more effective, and would enhance partnerships among devoted professionals.

- It is also recommended that special consideration be made regarding the LIFTT program.

Because LIFTT is a source of referral to LINCS, it is like the treatment, placement, and adoption units operating with horizontal connections to LINCS. However, because LIFTT takes only voluntary clients, it is a unique referral source to the whole LINCS system.

2. Consistency in mission, goals, objectives, and services requires attention.

The LINCS program has identified a regional mission that is responsive to the characteristics of its locale. The area is rural and more ethnically diverse than might be assumed. Parental drug and alcohol abuse, poverty, homelessness, poor health, and domestic violence are endemic to the region. There are relatively few voluntary social service organizations in the area, so residents depend primarily upon the public social service system. Public social services are located in separate agencies where professional social service providers are very independent. Further, there has been an increase in the cost of services for children entering the foster care system.

The mission developed by the LINCS program is most responsive to these factors, as well as federal child welfare outcomes (i.e., safety, permanency, and well-being). However, at the time of the program evaluation, the program had not developed shared program goals and objectives. Departments and agencies involved in LINCS could separately identify the numerous services available for foster children and families, but did not link those services to LINCS goals and objectives.

- It is recommended that integrated objectives or goals across the departments and agencies that make up LINCS be developed.

The goals will function to link the mission to the program objectives, while the program objectives will operationalize the mission.
Consistency among mission, goals, objectives, and services would enhance the horizontal linkage of the LINCS model conceptual design. Consistency in these areas would promote shared understanding, culture, and language among staff from different professional backgrounds and work experiences - a valuable contribution to interagency collaborative teamwork.

\section{Funding sources require attention.}

This study found that managers know about approximately 10 of the available federal funding streams. However, evidence suggests there are some 40-plus programs funding child welfare services across the nation $[21,22]$. Shasta County might be able to extend its collaborative efforts across the fiscal domain and increase federal participation in funding its programs. The effect would be an increase in the capacity of the service delivery system with little or no increase in county expenditures for the program.

This funding deficiency is not related to the performance of managers in Shasta County; rather, it is endemic to the child welfare system across the nation as a whole. It is a result of the fragmentation of child welfare services delivery systems.

- It is recommended that the LINCS collaborative effort be expanded to include fiscal staff from each department

These staff should be co-located and work to develop better information on and secure funding from both state and federal governments.

Integration of funding would enhance the vertical linkage of the LINCS conceptual design, and further education to increase LINCS staff's knowledge and information about the criteria and application process for various funding sources.

\section{The working relationship between LINCS staff and CPS} staff requires attention

This study revealed strong concern from CPS workers about their weak working relationships with LINCS staff, particularly with regard to the negative effects on clients. This relationship should be reassessed and improved.

- It is recommended that Department of Social Services policy and procedures regarding CPS be revised to reflect the change from the prior model to the LINCS model of service delivery

More collaborative service delivery would reduce the conflict and confusion that currently exist in delivery of interagency services for foster children and families and result in a more compatible system overall.

\section{- It is recommended that the LINCS collaborative, integrated, and coordinated services system be expanded to include staff from CS}

A joint action plan is needed to facilitate strong communication among supervisors and line workers from both CS and LINCS.

5. The working relationship between LINCS staff, foster parents, and CYC youth requires attention.

There are two separate considerations here. The first is that, in the course of this study, foster parents and CYC youth expressed serious concern regarding their understanding of the differences between LINCS and CPS. The majority of foster parents and foster youth did not even know what LINCS was. The second consideration has to do with the quality of the social worker response to CYC youth. About half the participants commented about the social workers' attitude toward foster youth. One young participant said, "Youth don't like someone who is stiff. Youth prefer someone who looks and talks with them like a friend."

- It is recommended that a planned introduction to LINCS be made a program for foster parents and CYC youth. LINCS staff should inform foster parents and CYC youth about the programs, 
services, resources, and opportunities available to them. This program introduction would decrease confusion and ambiguity about foster care services delivery and facilitate a partnership between the client and the worker.

- Many of the youth perceive that they are being treated with less compassion and concern than they would like. It is recommended that social workers understand this viewpoint and work on developing a stronger partnership with the youth in their system.

\section{Administrative leadership should be stabilized.}

During this study, an interim director headed LINCS because a new director, to replace one who retired, had not yet been hired. It is not surprising that we often heard focus-group members, especially supervisors and line workers, express concern about the interruption of administrative leadership (e.g., the gap between the former director's retirement and the new director's appointment). Although this issue has been resolved with the hiring of a new director, it highlights a need for long-term strategic planning among the departments and agencies in the program. Unclear thinking about future direction can lead to general confusion, both politically and organizationally. In addition, there may be many retirements in the next few years, making this strategic planning even more vital as a tool to deal with high turnover of department heads.

This study suggests that the LINCS model's dependence on committed leadership is its greatest weakness. Because it does not involve major governmental restructuring (i.e., at the upper and middle management levels), and because key leadership changed at the beginning of its development and growth, staff have become confused about the direction of the LINCS model. This is obviously an unexpected, unplanned consequence of the planned change in the service delivery process.

- It is recommended that strategic planning for child welfare services in the future be done (e.g., five-year plan, 10-year plan). Administrative leaders of interorganizational community-based entities must also be pathfinders. They must continue to see the many possibilities available to staff and help staff members focus on the challenges of working in what for many is a new, ambiguous, and more complex system. Leaders must perpetuate and continue to articulate the larger vision while constantly being aware of the smaller elements and how all those elements relate to the whole.

- It is recommended that administration include line staff and supervisors in significant policymaking and planning processes in the Children's Services Division.

7. Given that there are additional areas for improvements, it is recommended that the following improvements also be made.

- Improve space allocation.

There was a strong concern from staff at LINCS and staff at CPS were especially frustrated when they did not have enough rooms. Further, staff from CPS experienced emotional upset over the split between themselves and LINCS.

\section{- Reduce workloads}

Although workload has been reduced, the front-line staff and supervisors still harbor concern about their amount of work. The workload of the LINCS program manager is also very heavy. These concerns must be addressed. The core component for successful outcomes of the child welfare services program is the relationship between service provider and client. Caseload and workload sizes must be built on this basic premise, recognizing the essential nature of intervention in LINCS. regarding physical space limitations. The staff members at LINCS

\section{- $\quad$ Enrich cultural diversity.}

Additional thought should be given to enriching the diversity within the service context. As noted previously, the region is ethnically diverse, but the LINCS staff is not.

\section{Implications for Evaluation Research on Foster Care Programs}

The purpose of this qualitative process evaluation was to better understand what the LINCS program does, identify what is happening during the service delivery process, and improve the change efforts in the context of the multiagency collaborative partnership. "Collaboration primarily describes a process of bringing together two or more individuals (usually professionals) or organizations to coordinate efforts toward achieving a common goal" [23]. As Thornton et al. [23] emphasize, "while no two are identical, all collaborations involve partnerships that are ultimately concerned with outcomes, but rely heavily on the subtle processes of relationship building" (pp. 68-69).

There is a paucity of knowledge about how foster care services are delivered, and we lack a theoretical framework for assessing how the delivery structure and process for multiple services are operationalized in a multisystems collaboration. Understanding how to develop effective structures and processes for collaborative partnerships is very important for formulating foster care policy and procedures, foster care program success, and improvement of foster care services outcomes.

This study contributes knowledge about how multisystems collaborative partnerships work and do not work. This study is especially significant to an understanding of how multiple-services delivery structures and processes are operationalized contextually within multisystems collaborative partnerships. This includes child welfare workers' daily operations, collaborative working relationships, and financial relationships. This evaluative research fills a knowledge gap regarding the process of cooperation by making use of different disciplinary expertise, values, and experiences in the foster care system. Interestingly enough, this study supports earlier findings regarding the "core four" components identified as necessary for effective multidisciplinary collaborations: leadership, communication, cooperation, and shared vision [23].

More importantly, this study expands a philosophical and theoretical foundation of program evaluation research in foster care by shifting from positivism toward postmodernism [18]. This article presents a unique model of qualitative process evaluation of a foster care service delivery system with a multiple-systems perspective. Most program evaluation studies are quantitative and outcome-oriented, whereas this study is an in-depth, qualitative, process-oriented evaluation of a foster care program. Specifically, this study provides detailed information on diverse perceptions of working relationships among interagency directors, program managers, supervisors, and staff. To work effectively in a collaborative effort, it is necessary to recognize what the diversity of values, perceptions, and attitudes contributes to the overall process. As DePoy et al. [20] stress, "evaluation practice is the politicization of research and thinking and action process within social work practice at multiple system levels" (p. 13). This study models a "postmortem" approach to and theoretical and valuebased foundation for foster care program evaluation. This model of qualitative process evaluation of multisystems collaboration in foster care may be a powerful tool, enabling a better understanding of the strengths, issues, and processes that underlie development and implementation of a collaborative partnership program.

Conflict of Interest: The authors of this paper have no conflicts of interest to report.

\section{References}

1. Child Welfare Information Gateway. (2017) Foster care statistics 2015. Washington, DC: U.S. Department of Health and Human Services, Children's Bureau.

J Ment Health Soc Behav

Volume 1.2019. 107 
2. Child Welfare league of America (2017) California's Children .

3. Needell B, Webster D, Armijo M, Lee S, Dawson W, et al. (2013) Child welfare services reports for California. Retrieved from University of California at Berkeley Center for Social Services Research.

4. The Institute for Educational Leadership (2008) Program evaluation of the U.S. Department of Labor foster youth demonstration projects: Foster youth demonstration project: Final evaluation report. Washington, DC: Author.

5. McLean S (2012) Barriers to collaboration on behalf of children with challenging behaviours: A large qualitative study of five constituent groups. Child and Family Soc Work 17: 478-486.

6. Redmond P, Mabry R, Ball H, Wilson D, Brandes B, et al. (2012) Implementing a post-care service systems in child welfare: The Catawba County child wellbeing project (Frank Porter Graham Child Development Institute, the University of North Carolina at Chapel Hill).

7. Bernstein N (2000) A rage to do better: Listening to young people from the foster care system. San Francisco, CA: Pacific News Service.

8. Bundy-Fazioli K, Winokur M, DeLong-Hamilton T (2010) Placement outcomes for children removed for neglect. Child Welfare 88: 85-102.

9. Clark HB, Lee B, Prange ME, McDonald BA (1996) Children lost within the foster care system: Can wraparound service strategies improve placement outcomes? J Child \& Family Stud 5: 39-54.

10. Courtney ME, Piliavin I, Grogan-Kayor A, Nesmith A (2001) Foster youth transitions to adulthood: A longitudinal view of youth leaving care. Child Welfare 80: 685-717.

11. Evans EB (2002) The evaluation of the foster care program and services in Hardin County (Kent School of Social Work, University of Louisville).

12. Kimberlin S, Lemley A (2012) Policy brief: Demographics and outcomes of THP-Plus participants: Implications for extended foster care in California (John Burton Foundation policy brief).

13. Parrish T, DuBois J, Delano C, Dixon D, Webster D, et al. (2001) Education of foster group home children: Whose responsibility is it? Study of the educational placement of children residing in group homes final report. Sacramento, CA: California Department of Education.

14. Green RS, Ellis PT (2007) Linking structure, process, and outcome to improve group home services for foster youth in California. Evaluation and Program Planning 30: 307-317.

15. den Dunnen W, Stewart SL, Currie M, Willits E, Baiden P (2013) Predictors of out-of-home placement following residential treatment. Children and Youth Services Rev 35: 518-524.

16. D'Emidio-Cason M, Brown JH (1999) The other side of the story: Student narratives on the California drug, alcohol, and tobacco education programs. In A. K. Malinki (Ed.), Cases in qualitative research (pp. 142-153). Los Angeles, CA: Pyrczak Publishing.

17. Slutsky A (2013) Group homes vs. foster care.

18. Royse D, Thyer BA, Padgett DK, Logan TK (2010) Program evaluation: An introduction (5th ed.) Belmont, CA: BrooksCole.

19. Kitzinger J (2004) The methodology of focus groups: The importance of interaction between research participants. Soc Health \& Illness 16: 103-121.

20. DePoy E, Gilson, SF (2003) Evaluation practice: Thinking and action principles for social work practice. Pacific Grove, CA: Brooks/Cole-Thomson Learning.
21. Geen RS, Boots W, Tumlin KC (1999) The cost of protecting vulnerable children: Understanding federal, state, and local child welfare spending (Occasional Paper No. 20). Washington, DC: The Urban Institute.

22. U.S. House of Representatives, Ways and Means Committee. (2000) The 2000 green book (17th ed.). Washington, DC: U.S. Government Printing Office.

23. Thornton PL, Okundaye JN, Harrington D (2007) The training process of the Maryland Guardianship Assistance Project: A collaborative model for kinship foster care. Child Welfare 86: 67-88. 